\title{
DPE: Assessorando a SEDAP do Novo Tempo
}

Criada em abril de 1987 para prestar assessoramento ao ministro-chefe da Secretaria de Administração Pública da Presidência da República (SEDAP) e aos programas e projetos considerados especiais pelo Conselho Diretor da FUNCEP, a Diretoria de Projetos Especiais (DPE) definiu 12 temas de trabalho, entre os quais, estudos para instalação e fortalecimento do Conselho Interministerial de Remuneração e Proventos (CIRP) e a Análise da remuneração do servidor público da administração direta de 1977 a 1987.

\section{O CIRP foi instalado e fortalecido para dar tratamento específico à questão salarial dos servidores da administração direta e autarquias}

Segundo o Diretor da DPE, Leônidas Macedo - que atualmente acumula a função de secretário-executivo do CIRP - , o estudo realizado para a instalação do CIRP partiu da necessidade, identificada pelo ministro Aluizio Alves, de um tratamento diferenciado dos salários dos funcionários públicos da administração direta e das autarquias. Até então, conta o diretor, quem tratava do assunto era - Conselho Interministerial de Salários das Estatais (CISE). Assim a partir dos estudos desenvolvidos pela DPE, o CIRP, que tinha sido criado em 1985 mas não tinha conseguido se firmar, foi instalado e fortalecido para dar tratamento específico à questão salarial dos servidores federais da administração direta e das autarquias, ficando para o CISE a questão salarial das estatais.

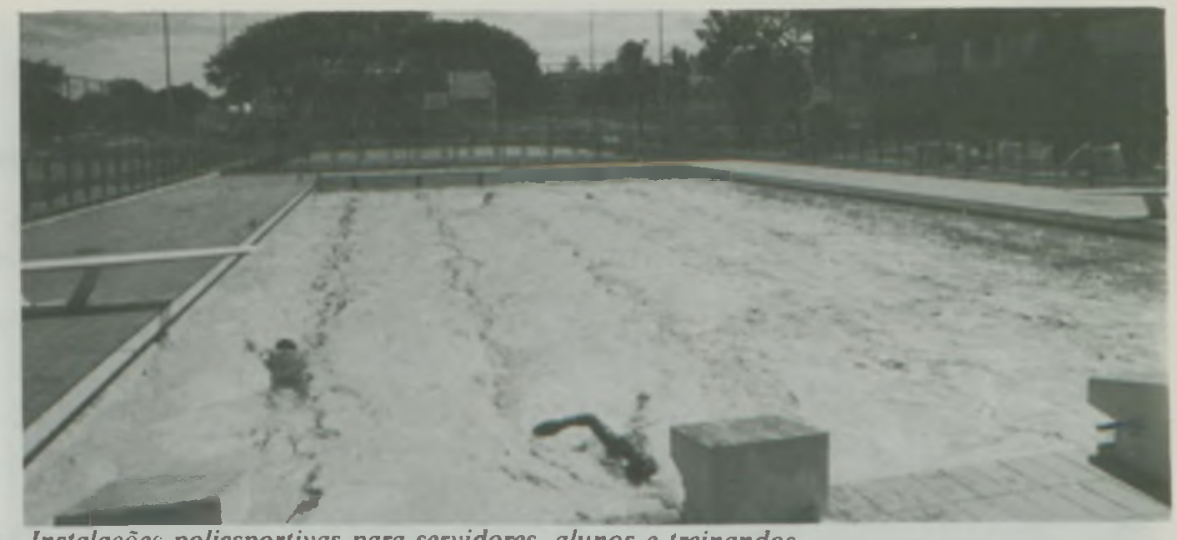

Instalaçōes poliesportivas para servidores, alunos e treinandos.

O segundo trabalho executado pela DPE, de acordo com depoimento de seu diretor, foi a análise da remuneração do servidor público da administração direta, no período de 1977 a 1987. O levantamento identificou ano a ano, o nivel de crescimento ou de perda salarial nesses 10 anos. O resultado foi alarmante, quando ficou demonstrada a defasagem salarial dos servidores federais da administração direta registrada até 85 , época em que, segundo Leônidas Macedo, se verificou uma recuperação expressiva dos salários. Para o Diretor da DPE, essa recuperação ocorreu devido à política adotada pelo Governo Federal

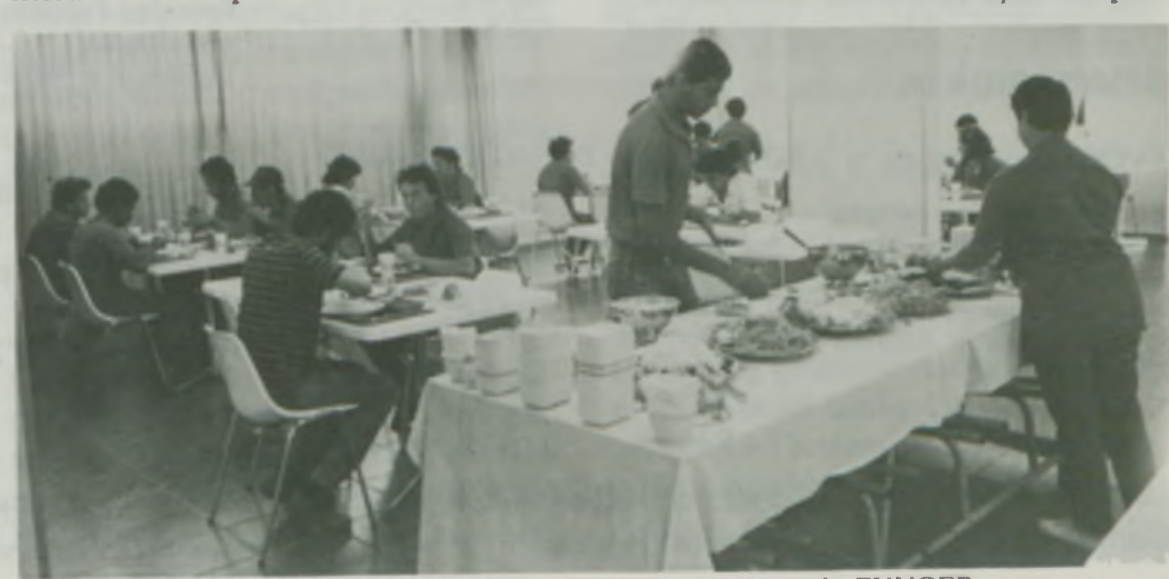

Restaurante aparelhado para atender publico interno e externo da FUNCEP. e implementada pelo ministro Aluízio Alves, de conceder reajustes salariais aos servidores acima da inflação do periodo.

Realizamos, por delegação de competência da SEDAP, recrutamento e seleção de pessoal civil para a Administração Pública

CONCURSOS

A FUNCEP realizou, por delegação de competência da SEDAP, vários concuros públicos com vistas ao recrutamento e a seleção de pes- 


\section{CAPA}

soal civil para a administração pública, até que em janeıro aeste foram proibidas novos concursos. A partir dai. com a experiência acumulada, a FUNCEP tem sido procurada por diversos órgãos da administração estadual e municipal para prestar esse tipo de serviço.

Durante o período de abril a dezembro de 1987 , os concursos públicos delegados à FUNCEP, pela SEDAP, foram realizados pela Diretoria de Projetos Especiais. Segundo relatório da Diretorıa desse período, foram feitos os seguintes concursos: Secretaria Municipal de Saúde da cidade de Natal, concursos para diversas categorias em órgãos federais de 12 Estados, Escola Agrotécnica Federal de Araguaina (GO) e processo seletivo interno do IBGE em todo o País.



CURSOS SOBRE PLANEJAMENTO E ADMINISTRACÃO (1)



CURSOS DE APERFEICOAMENTO E DESENVOLVIMENTO GERENCIAL (1)

\begin{tabular}{|c|c|c|c|}
\hline EVENTO & PERIODO & DURAÇÃO & CUSto \\
\hline Noçōes de Gerência & $\begin{array}{l}12 / 9 \text { a } 23 / 9 \\
17 / 10 \text { a } 28 / 10\end{array}$ & $\begin{array}{l}40 \mathrm{~h} / \mathrm{a} \\
40 \mathrm{~h} / \mathrm{a}\end{array}$ & 5.400 , \\
\hline $\begin{array}{l}\text { Chefia e Liderança } \\
\text { Técnica de Conducão }\end{array}$ & $21 / 11$ a & $40 \mathrm{~h} / \mathrm{a}$ & \\
\hline $\begin{array}{l}\text { Reuniōes } \\
\text { Programa Integrado }\end{array}$ & $29 / 9$ a $7 / 10$ & $40 \mathrm{~h} / \mathrm{a}$ & 5.4 \\
\hline Gestão - PRIMA & $\begin{array}{l}3 / 10 \text { a } 24 / 10 \\
3 / 10 \text { a } 24 / 10 \\
7 / 11 \text { a } 28 / 11 \\
7 / 11 \text { a } 28 / 11\end{array}$ & $\begin{array}{l}90 \mathrm{~h} / \mathrm{a} \\
90 \mathrm{~h} / \mathrm{a} \\
90 \mathrm{~h} / \mathrm{a}\end{array}$ & \\
\hline
\end{tabular}

\section{CURSO PARA AUXILIAR E APOIO ADMINISTRATIVO}

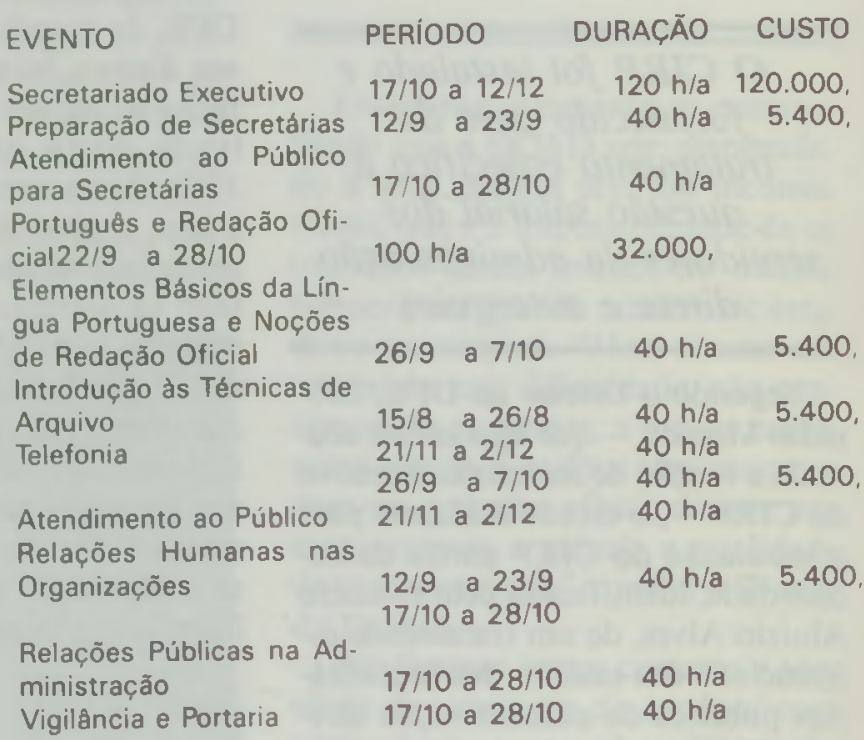

(1) Local de realização dos cursos: Brasília/DF Informações e Inscrições:

Gerência de Apoio Administrativo e Didático

FUNCEPISAIS, C.P. 12-2555 - Fone: 245-5909

Ramais 197 e 227 - 70.610 - Brasília/DF

\section{SEDAP/FUNCEP/CEDAM}

Um novo tempo na Administração Pública 